\title{
Control of supplementary feedback cue properties by differentiation and extinction procedures*
}

\author{
R. B. PAYNE and E. T. RICHARDSON $\dagger$ \\ University of Georgia, Athens, Georgia 30602
}

\begin{abstract}
If classically predifferentiated supplementary feedback cues promote psychomotor learning through the operation of conditional properties, as prior studies have suggested, one should be able to nullify such effects by conventional extinction procedures. The present study examined this implication. After preliminary tracking practice under common conditions, 88 Ss were assigned in equal numbers to (1) aversive differentiation of to-become supplementary error (CS+) and targeting (CS-) cues, (2) differentiation followed immediately by extinction trials, (3) CS-only controls, and (4) neutral controls. Subsequently, all groups tracked under common conditions of cue availability and withdrawal. Once again, predifferentiation transformed otherwise ineffective cues into significant learning supports. Contrary to expectation, however, extinction trials failed to nullify their effects on performance. This failure was rationalized in terms of the known resistance of aversive CRs to extinction and/or possible reconditioning of the cues during the tracking trials.
\end{abstract}

Do redundant supplementary feedback cues facilitate psychomotor performance? If so, how persistent are the effects when the cues are withdrawn? Consistent answers to these questions are not available (Bilodeau, 1966; Bilodeau, 1969). Indeed, one can find evidence for learning effects (Reynolds \& Adams, 1953; Williams \& Briggs, 1962), transient performance effects (Bilodeau, 1952; Smode, 1958), and no effects at all (Archer \& Namikas, 1958; Bilodeau \& Rosenquist, 1964). When effects do occur, the learning-performance distinction sometimes depends upon the clarity of intrinsic cues (Kinkade, 1963), but numerous exceptions exist.

Payne (1970) and Payne and Artley (1972) proposed that otherwise nugatory supplementary indicants of tracking proficiency might be made effective by contriving some sort of reactional history that would endow them with biographical significance. They employed an aversive UCS to invest green and red signals with differential conditional properties, then made the onsets of green ( $\mathrm{CS}-$ ) and red ( $\mathrm{CS}+$ ) contingent upon wanted and unwanted tracking responses. Under these conditions, tracking proficiency was a negatively accelerated increasing function of the number of differentiation trials; this facilitative effect persisted throughout bilateral transfer trials despite supplementary cue withdrawal. By conventional inference, therefore, the cues affected learning as well as performance. Further studies rejected the hypothesis that performance gains reflected arousal and/or warm-up effects of shock and signal preview (Payne \& Richardson, 1972; Payne \& Dunman, 1974). Instead, the functional properties of the cues were traced

*This paper is based upon a thesis submitted by the junior author in partial fulfillment of the requirements for the MS degree at the University of Georgia.

tNow with the Savannah (Georgia) Public School System. unequivocally to differentiation itself. Their effects upon tracking were regarded as having exemplified the operation of secondary reinforcement principles and perhaps secondary drive and punishment principles as well.

Conditional properties, of course, are subject to the laws of extinction. One should, therefore, be able to nullify the performance effects of differentiated supplementary feedback cues by extinction procedures. The present study was concerned with this implication.

\section{METHOD}

\section{Subjects}

The sample consisted of 88 right-handed $(\mathrm{RH})$ Caucasian females enrolled in introductory psychology courses. Modal age was 18 years.

\section{Task}

As previously described (Payne \& Artley, 1972), Ss were required to use mirror vision in order to keep a stylus in contact with a small silver target as it moved clockwise at $1 \mathrm{rpm}$ through a narrow star-shaped pathway. Ss were told to stay on target and avoid touching the sides of the pathway. Time on target (TOT) and time against the sides of the pathway (TAS) were obtained for each minute of the practice sequence.

Supplementary feedback was provided by green and red lamps located just inside the distal edge of the trackplate. When $\mathrm{E}$ made this feedback available to $S$, the green signal was contingent only upon target contact, while the red signal was contingent only upon contact with either side of the pathway. Neither signal appeared when both contacts were made concurrently. All contacts were clearly perceptible without assistance from the supplementary cues.

\section{Procedure}

Ss were assigned in equal numbers to four treatment groups. Group 1 practiced RH tracking for 2 min without supplementary feedback, then moved over to another apparatus for 24 cue differentiation trials. This sequence consisted of 12 green and 12 red signals presented one at a time in random order. The duration of each signal was $1 \mathrm{sec}$, and the interval between onsets was $4 \mathrm{sec}$. A green signal was always followed by an 
uneventful interval, while a red signal was followed instantaneously by an electric shock delivered to the fingers of the RH by a Physiological Electronics Stimulator (Model 702) at a setting of 1,500 microcoulombs. After differentiation, Ss were given extinction trials consisting of 36 green and red signals presented equally often one at a time in random order. The length of this sequence was determined by a pilot study in which three 12-light series, separated by 5 -min rests for spontaneous recovery, were found adequate to extinguish a conditional GSR following a 24-light differentiation series.

After extinction trials, Group 1 returned to the tracking task for $18 \mathrm{~min}$ continuous RH practice. During the first $10 \mathrm{~min}$ of this, Ss received a green signal when on target and not against the side and a red signal when against the side and not on target. Following RH practice, Ss shifted the stylus abruptly to the $\mathrm{LH}$ for $10 \mathrm{~min}$ continuous practice. The interval between pre- and posttreatment tracking trials was $15 \mathrm{~min}$.

Group 2 followed the same procedure as Group 1 except for extinction trials. Group 3 rested throughout the entire 15-min treatment in terval, but otherwise followed the same procedure as Groups 1 and 2. Group 4 served as a control for possible effects of signal preview per se. After preliminary practice, Group 4 received 60 signals in the same sequence as Group 1 , but without shock. Thereafter, Group 4 followed the common practice sequence.

\section{RESULTS}

Average TOT and TAS for each $\mathrm{S}$ were calculated for successive 2-min practice blocks and averaged within treatments. Resulting performance trends are shown in Figs. 1 and 2.

Although a blockwise analysis of treatment effects would obviously provide more detail, the purposes of the study were believed adequately and economically served by analyses of the bilateral transfer blocks. These, of course, provided the most stringent test of the persistence of learning differentials initiated during the supplementary feedback trials.

\section{Target Scores}

The four treatment groups performed essentially alike during the preliminary practice period $(\mathrm{F}=1.16, \mathrm{df}=$ $3 / 84, p>05$ ). However, a mixed factorial variance analysis of transfer scores revealed significant

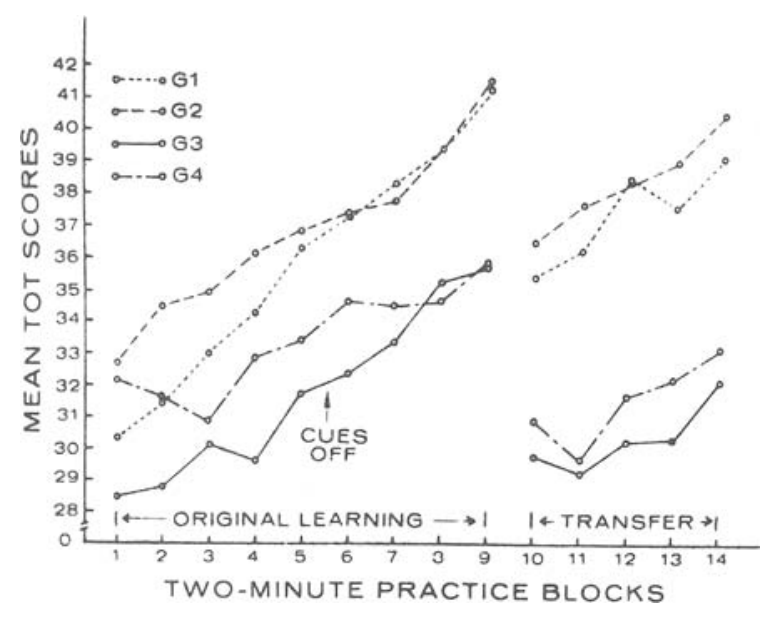

Fig. 1. Group trends of TOT scores.

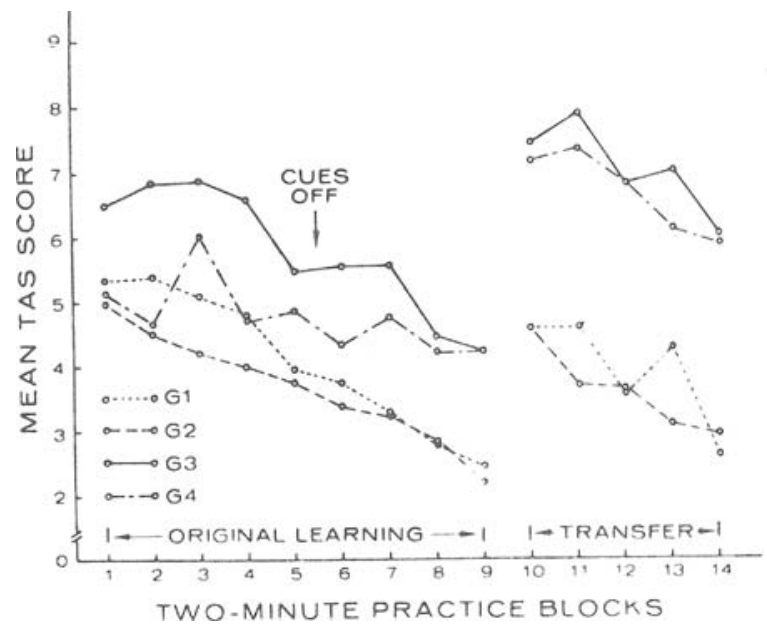

Fig. 2. Group trends of TAS scores.

treatment effects $(F=4.76, d f=3 / 84, p<.005)$ and block effects $(F=14.12, \mathrm{df}=4 / 336, \mathrm{p}<.001)$. Two-tailed $t$ tests of simple treatment effects showed that the means of Groups 1 and 2 were both significantly larger than the means of Groups 3 and 4 $(p<.01)$. No other differences were significant.

\section{Error Scores}

As was the case with target scores, mean TAS scores during preliminary practice were quite similar $(\mathrm{F}<1)$. However, a mixed factorial variance analysis of the transfer scores yielded significant treatment effects $(\mathrm{F}=$ $4.38, \mathrm{df}=3 / 84, \mathrm{p}<.01)$ and block effects $(\mathrm{F}=10.34$, $\mathrm{df}=4 / 336, p<.001)$. Two-tailed $t$ tests of simple treatment effects showed that the means of Groups 1 and 2 were both significantly lower than those of Groups 3 and $4(\mathrm{p}<.05)$. No other differences were significant.

\section{DISCUSSION}

The foregoing outcomes could scarcely be more clear. As in previous studies of this series, predifferentiation of otherwise ineffective supplementary feedback cues transformed them into effective learning supports. Also, the null effects of signal preview per se corroborated the results of Payne and Dunman (1974). Contrary to expectation, however, extinction trials failed to achieve a reliable reduction of cue effects on performance. In one sense, this failure strengthens the case for the alleged role of such cues because performance effects occurred despite rational efforts to preclude them. At the same time, however, it poses the mystery of how to get rid of such effects once the germinal conditions have been established.

The failure of the 36 extinction trials to neutralize the functional properties of the cues can no doubt be rationalized in various ways. The most obvious possibility, of course, involves the question of whether the trials were numerically sufficient. Although GSR extinguished readily in the pilot study, as it is wont to do, it was, after all, only one component of a collectivity of autonomic and skeletal responses elicited by the UCS, all of which were presumably differentially conditioned to some degree. The extinguishability of GSR says nothing very precise about the fate of other response components. As long as the cues remained differentially conditional for some of these components, a mechanism remained for the subsequent 
mediation of tracking effects through the operation of conditional properties. This view has the merit of consistency with the known facts about resistance of an aversive CR complex to extinction.

A somewhat less obvious possibility, conjoined with or alternative to the first, assumes that some extinction of the CR complex did in fact occur, but that reconditioning of the cues took place over the span of tracking trials involving supplementary feedback. ${ }^{1}$ Support for this view is suggested by Fig. 1, in which Group 1 began $\mathrm{RH}$ practice with less proficiency than Group 2, yet gained more rapidly so that the two curves were essentially equal from Block 6 onward. However, if reconditioning occurred, what was the UCS? The reader will recall that Ss were warned not to touch the sides of the pathway. Side contact, an intrinsic cue, was therefore at least mildly aversive. Since its duration was coextensive with the red signal, the requirements of a simultaneous paradigm were satisfied. It was obviously not aversive enough to affect the cues in Groups 3 and 4 , but it might have been aversive enough to restore conditional properties in Group 1. This view is consistent with the known facts about the progressive ease with which reconditionings occur.

\section{REFERENCES}

Archer, E. J., \& Namikas, G. A. Pursuit rotor performance as a function of delay of information feedback. Journal of Experimental Psychology, 1958, 56, 325-327.

Bilodeau, E. A. Some eff ects of various degrees of supplemental information given at two levels of practice upon the acquisition of a complex motor skill. USAF Human R esources Center R esearch Bulletin, 1952, No. 52-15.

Bilodeau, E. A. Supplem entary feedback and instructions. In E.
A. Bilodeau (Ed.), Principles of skill acquisition. New York: Acad emic Press, 1969.

Bilodeau, I. McD. Information feedback. In E. A. Bilodeau (Ed.), Acquisition of skill. New York: Academ ic Press, 1966.

Bilodeau, I. McD., \& Rosenquist, H. S. Supplementary feedback in rotary-pursuit tracking. Journal of Experimental Psychology, 1964, 68, 53-57.

Kinkade, R. G. A diff erential influence of augmented feedback on learning and on performance. USAF AMRL Technical Documentary R eport, 1963, No. 63-12.

Payne, R. B. Functional properties of supplementary feedback stimuli. Journal of Motor Behavior, 1970, 2, 37-43.

Payne, R. B., \& Artley, C. W. Facilitation of psychomotor learning by classically differentiated supplementary feedback cues. Journal of Motor Behavior, 1972, 4, 47-55.

Payne, R. B., \& Dunman, L. S. Effects of classical predifferentiation on the functional properties of supplementary feedback cues. Journal of Motor Behavior, $1974,6,47-52$.

Payne, R. B., \& Richardson, E. T. Effects of classically differentiated supplem entary feedback cues on tracking skill. Journal of Motor Behavior, 1972, 4, 257-261.

Reynolds, B., \& Adams, J. A. Motor performance as a function of click reinforcement. Journal of Experimental Psychology, $1953,45,315-320$.

Smode, A. F. Learning and performance in a tracking task under two levels of achievement information feedback. Journal of Experimental Psychology, 1958, 56, 297-304.

Williams, A. C., \& Briggs, G. E. On-target versus off-target information and the acquisition of tracking skill. Journal of Experimental Psychology, 1962, 64, 519-525.

\section{NOTE}

1. The authors are indebted to Avrum I. Silver for suggesting this possibility and for a critical review of the paper.

(R eceived for publication May 17, 1974.)

\title{
Recall of attitudinal and value belief statements in in terpersonal judgment tasks*
}

\author{
ANNE V. GORMLY \\ Trenton State College, Trenton, New Jersey 08625
}

\begin{abstract}
The theoretical distinctions between attitude and value statements were investigated, using two interpersonal-judgment situations. Recall of attitude and value beliefs and the effect of similarity of views on attraction were of interest. Predictions from Rokeach's belief centrality theory suggested the saliency of value beliefs over attitude beliefs in judgment settings. In Study I, 102 undergraduates were given booklets, attributed to a bogus stranger, which contained either attitude or value statements. The responses to the statements were manipulated to agree or disagree with the Ss' opinion, using one of three levels of similarity $(25 \%, 50 \%$, or $75 \%$ agreement). Ss tended to have better recall of value topics $(p<.10)$. Attitude statements, however, were rated as being more useful in making judgments about the bogus stranger $(p<.05)$. There was a significant effect for level of similarity on the attraction measures $(p<.005)$. In Study II, 114 Ss met an accomplice face to face and exchanged either attitude or value statements. This similarity of the accomplice and $S$ was one of four levels $(0 \%, 33 \%, 67 \%$, or $100 \%$ agreement). Attitude statements were more useful $(p<.05)$ than value beliefs, and recall data favored value statements $(p<.05)$. There was a significant similarity effect $(p<.05)$ for attraction measures.
\end{abstract}

*This research was supported in part by a grant from the Faculty and Institutional Research Committee, Trenton State College. The paper was sponsored by H. Richard Schiffman, who takes full editorial responsibility for its contents. Christopher Guliano, James Labella, Edward Sarnoski, Carol Schenck, Phillip Schlissel, Lou ise Stirpe, and Paula Sullivan all assisted in the data collection. Requests for reprints should be mailed to the author, Department of Psychology, Trenton State College, Trenton, New Jersey 08625 .
Experimental research in social psychology has been remiss in empirically demonstrating the distinction between attitudes and values. The basic task of human-memory recall may provide a paradigm for investigating this substantive distinction.

The following study involved two separate 